\title{
Legislación aplicable a los servicios electrónicos en unidades documentales
}

José Luis Cárceles Andreu

Isabel Andreu Felipe

Carmen María Brugarolas Ros

Concepción Dolores Alcázar Ruiz

Comunidad Autónoma de la Región de Murcia (España)

\section{Resumen}

Se han clasificado los distintos servicios electrónicos que ofrecen las unidades documentales en tres grandes bloques en función de la legislación aplicable en materia de protección de datos de carácter personal, medidas de seguridad de los ficheros automatizados que contengan datos de carácter personal, servicios de la sociedad de la información y comercio electrónico y propiedad intelectual de los contenidos, así como la accesibilidad de las páginas web de los nuevos servicios electrónicos proporcionados por estos centros.

Palabras clave: Servicios electrónicos. Protección de datos. Propiedad intelectual. Accesibilidad.

\section{Abstract}

The different electronic services that are commonly offered by information and documentation units have been classified into three main groups, according to the legislation that must be applied with regard to the protection of personal data, services for the Information Society and e-Business, intellectual property and web accessibility.

Keywords: Electronic services. Data protection. Intellectual property. Accessibility.

Las unidades documentales dependientes de cualquier institución, ya sea un organismo público o una empresa privada, están ofreciendo en los últimos tiempos a sus usuarios una serie de servicios de valor añadido complementarios de los servicios considerados como tradicionales en estos centros.

Dichos servicios estarían englobados dentro de lo que últimamente se está denominando servicios de la sociedad de la información y servicios de intermediación, ya que no se hace necesaria una comunicación directa y física entre dos

Scire. $14: 2$ (jul.-dic. 2008) 161-165. ISSN 1135-3716. 
personas para la prestación de un servicio, sino que dicha comunicación se establece por medios telemáticos utilizando las redes de comunicaciones actuales, y entre ellas la red Internet es la más utilizada.

En la interactividad producida en la relación que los usuarios mantienen con los servicios ofertados por las unidades documentales, aspectos legales de dicha comunicación, como por ejemplo la protección de datos de carácter personal, están bastante claros. Sin embargo, con la llegada de las nuevas formas de comunicación con los usuarios se hace necesario establecer una serie de medidas para incorporar la legislación vigente en materia de protección de datos de carácter personal, medidas de seguridad de los ficheros automatizados que contengan datos de carácter personal, servicios de la sociedad de la información y comercio electrónico y propiedad intelectual de los contenidos, así como la accesibilidad de las páginas web a los nuevos servicios electrónicos proporcionados por estos centros.

Servicios desarrollados hasta hace poco tiempo de forma presencial en los propios centros documentales o productos informativos difundidos en formato impreso se están realizando por medios electrónicos. A los servicios considerados como básicos en un centro de documentación se están incorporando otros nuevos gracias a las nuevas tecnologías de la información y la comunicación.

Se han clasificado los servicios electrónicos a los que les afecta la legislación aplicable en tres grandes bloques: 1) comunicaciones con los usuarios, 2) información almacenada en soporte electrónico y 3 ) servicios web.

Dentro de las comunicaciones llevadas a cabo con los usuarios por las unidades documentales se está extendiendo el uso del correo electrónico para servicios tales como boletines de novedades bibliográficas, petición de publicaciones, reserva en el préstamo de publicaciones, listas de distribución, servicios de difusión selectiva de información y, sobre todo, servicio de referencia a través de las consultas bibliográficas en la Web.

En todos los servicios electrónicos mencionados anteriormente se hace necesario incluir, en las comunicaciones efectuadas con los usuarios mediante correo electrónico, una cláusula donde se refleje el uso y tratamiento que se va a llevar a cabo con los datos personales proporcionados, siguiendo los preceptos de la Ley Orgánica 15/1999, de 13 de diciembre, de Protección de Datos de Carácter Personal.

En este mismo sentido se encuentran las listas de distribución utilizadas como medio de comunicación entre los usuarios y las unidades documentales para la prestación se determinados servicios. Dichas listas de distribución deben incluir en los formularios web de alta de usuarios una nota, cláusula o aviso legal donde se informe del tratamiento dado a los datos proporcionados, según dictan los artículos 5 y 6 de la citada ley. 
También deben incluir la posibilidad de modificación o rectificación de dichos datos, así como la opción de darse de baja de la lista de distribución y no recibir más mensajes mediante otro formulario web, siguiendo la legislación mencionada anteriormente, así como la Ley 34/2002, de 11 de julio, de Servicios de la Sociedad de la Información y de Comercio Electrónico.

Como ejemplo de lo dicho cabe citar la cláusula incluida en los mensajes de la lista de distribución para profesionales de las áreas de trabajo y servicios sociales del centro de documentación de la Consejería de Trabajo y Política Social de la Comunidad Autónoma de la Región de Murcia, que dice lo siguiente:

En cumplimiento de la Ley 34/2002, de 11 de julio, de Servicios de la Sociedad de la Información y de Comercio Electrónico, le comunicamos que si no desea recibir más mensajes puede darse de baja o modificar sus datos a través del siguiente enlace: http://www.carm.es/ctra/CENDOC/listas/.

En lo relacionado con la información almacenada en soporte electrónico en las unidades documentales, hay que tener en cuenta los distintos tipos de ficheros que se generan en las mismas. Básicamente estaríamos hablando de los ficheros de usuarios y del historial de préstamos. A estos ficheros de uso interno de la unidad documental se les debe aplicar lo expuesto al respecto en la Ley Orgánica 15/1999, de 13 de diciembre, de Protección de Datos de Carácter Personal y en el Real Decreto 994/1999, de 11 de junio, por el que se aprueba el reglamento de medidas de seguridad de los ficheros automatizados que contengan datos de carácter personal.

En una cláusula en los formularios web de alta se debe informar a los usuarios de que los datos suministrados quedarán incorporados a un fichero automatizado que será procesado exclusivamente para la finalidad descrita, y que dichos datos se recogerán a través de los mecanismos correspondientes, los cuales solo contendrán los campos imprescindibles para poder prestar el servicio requerido por el usuario.

Además debe advertir que los datos de carácter personal serán tratados con el grado de protección adecuado y que se tomarán las medidas de seguridad necesarias para evitar su alteración o pérdida, así como el tratamiento o acceso no autorizado por parte de terceros que lo puedan utilizar para finalidades distintas de aquellas para las que han sido solicitados al usuario.

Finalmente, dicha cláusula debe indicar que los datos de carácter personal objeto de tratamiento automatizado solo podrán ser cedidos, según consta en el artículo 11 de la Ley Orgánica 15/1999, de 13 de diciembre, de Protección de Datos de Carácter Personal, para el cumplimiento de fines directamente relacionados con las funciones legítimas del cedente y del cesionario, con el previo consentimiento del afectado.

En cuanto a los servicios web ofertados en las páginas y portales de las unidades documentales, hay que mencionar el uso de cláusulas de exención de Scire. 14 : 2 (jul.-dic. 2008) 161-165. ISSN 1135-3716. 
responsabilidad en lo referente a los contenidos electrónicos. Dichas cláusulas deben comunicar a los usuarios que el acceso y el uso de las páginas web y portales, así como de los servicios ofrecidos, están sujetos a una serie de términos de uso y derechos de propiedad intelectual e industrial. Se tiene que informar sobre la utilización indebida o no autorizada de la información contenida en los servicios web, así como sobre los perjuicios que se puedan ocasionar en los derechos de la propiedad intelectual de la unidad documental, que darán lugar a las acciones que legalmente correspondan a dicha unidad y, en su caso, a las responsabilidades que de dicho ejercicio se deriven.

Igualmente, las cláusulas de exención de responsabilidad deben informar de que la unidad documental no es responsable de la información que se pueda obtener a través de los enlaces externos que no sean dependientes del centro, y que tanto el acceso a los servicios electrónicos como el uso que pueda hacerse de la información contenida en los mismos son de la exclusiva responsabilidad de quien lo realiza.

Y, por último, se ha de advertir que la unidad documental no se hace responsable de ninguna consecuencia, daño o perjuicio que pudieran derivarse de dicho acceso o uso de la información, con excepción de todas aquellas que resulten de la aplicación de las disposiciones legales a las que deba someterse en el estricto ejercicio de sus competencias.

Como ejemplo de todo lo expuesto anteriormente, este es un extracto de los términos de uso del portal sanitario de la Comunidad Autónoma de la Región de Murcia:

La utilización de estos servicios significa su aceptación, sin reservas de ninguna clase, a todos y cada uno de los términos y condiciones expuestos. MURCIASALUD contiene vínculos a otras páginas Web y otros servicios propiedad de sus respectivos productores; el uso por su parte de cualquier página o servicio de MURCIASALUD significa asimismo la aceptación respectiva de las condiciones de uso contenidas, en su caso, en cada página o servicio correspondiente.

Aunque dichos enlaces son revisados periódicamente, puede ocurrir que los contenidos o la propiedad de estas páginas cambien, en cuyo caso MURCIASALUD queda exonerada de toda responsabilidad frente al usuario en cuanto a las condiciones de utilización y contenidos de las diferentes páginas Web.

$[\ldots]$

Los textos, diseños, imágenes, bases de datos, logos, estructura, marcas y demás elementos de este sitio están protegidos por las Leyes y los tratados internacionales sobre propiedad intelectual e industrial. Cualquier reproducción, transmisión, adaptación, traducción, modificación, comunicación al público, o cualquier otra explotación de todo o parte del contenido de este sitio, efectuada de cualquier forma o por cualquier medio, electrónico, mecánico u otro, están estrictamente prohibidos salvo autorización previa por escrito de MURCIASALUD. Cualquier infracción de estos derechos puede dar lugar a procedimientos extrajudiciales o judiciales civiles o penales que correspondan.

Scire. 14 : 2 (jul.-dic. 2008) 161-165. ISSN 1135-3716. 
Finalmente, hay que indicar que los servicios electrónicos ofertados por cualquier unidad documental deben cumplir con una serie de requisitos y de normas en cuanto a su accesibilidad por parte de personas discapacitadas.

La accesibilidad de las páginas web está recogida en unas recomendaciones del World Wide Web Consortium (W3C) denominadas Pautas de accesibilidad al contenido en la Web, cuyo objetivo es facilitar el acceso de las personas con discapacidad desarrollando pautas de accesibilidad y mejorando las herramientas para la evaluación y reparación de accesibilidad web.

\section{Referencias}

Agencia de Protección de Datos de la Comunidad de Madrid (2003). Manual de protección de datos para las Administraciones Públicas. Madrid: Comunidad de Madrid, 2003.

Consejería de Trabajo y Política Social de la Comunidad Autónoma de la Región de Murcia (2003). Diseño de páginas web accesibles. Murcia: Consejería de Trabajo y Política Social, 2003. http://www.carm.es/ctra/cendoc/publicaciones (2005-03-30).

Magán Walls, José Antonio (2002). Tratado básico de biblioteconomía. Madrid: Editorial Complutense, 2002, $4 .^{\text {a }}$ ed.

Quinto Zumárraga, Francisco (2004). La firma electrónica: marco legal y aplicaciones prácticas. Barcelona: Grupo Difusión, 2004.

Rubio Navarro, Antonio María (2004). Aspectos básicos de la protección de datos de las personas físicas. Barcelona: Bosch, 2004. 